\title{
Генезис сынныритов Сыннырского массива по данным изучения расплавных включений в апатите
}

\author{
Панина Л.И., Рокосова Е.Ю., Исакова А.Т., Рябуха М.А. \\ Институт геологии и минералогии СО РАН, Новосибирск, panina@igm.nsc.ru
}

\begin{abstract}
Аннотация. Сынныриты - это уникальные ультракалиевые алюмосиликатные породы, состоящие из симплектитовых срастаний калишпата, кальсилита и нефелина. В статье впервые приводятся прямые данные о кристаллизации сынныритов Сыннырского плутона из магматических расплавов. Эти результаты были получены при изучении первичных расплавных включений в апатите сынныритов. Было установлено, что прогретые до $1100-1150^{\circ} \mathrm{C}$ расплавные включения содержат (мас. \%): 53-56 $\mathrm{SiO}_{2}, 22-24 \mathrm{Al}_{2} \mathrm{O}_{3}, 12.4-17.6 \mathrm{~K}_{2} \mathrm{O}$, а также пониженные количества $\mathrm{FeO}$, особенно $\mathrm{MgO}$ и $\mathrm{CaO}$ (0-0.2, 0-0.1 и 0.4-3.6 мас. \%, соответственно). Эти составы близки к сынныритам и их переходным разностям с нефелиновыми сиенитами. Появление подобных расплавов связано с длительной и достаточно полной дифференциацией щелочных магм в условиях, приближающихся к закрытым системам, что в природе встречается крайне редко.
\end{abstract}

Ключевые слова: сынныриты, нефелин, кальсилит, калишпат, апатит, расплавные включения, генезис.

\section{Genesis of synnyrites from the Synnyr massif: study of melt inclusions in apatite}

\author{
Panina L.I., Rokosova E.Yu., Isakova A.T., Ryabukha M.A. \\ V.S. Sobolev Institute of Geology and Mineralogy, Novosibirsk, panina@igm.nsc.ru
}

\begin{abstract}
Synnyrites are very unique ultrapotassic aliminosilicate rocks containing symplectites of K-feldspar, kalsilite, and nepheline. The first direct data about magmatic crystallization of synnyrites from the Synnyr massif are given in this issue. These data were obtained by study of primary melt inclusions in apatite from synnyrites. Apatitehosted melt inclusions heated up to $1100-1150^{\circ} \mathrm{C}$ contain (in wt. \%) $53-56 \mathrm{SiO}_{2}, 22-24 \mathrm{Al}_{2} \mathrm{O}_{3}, 12.4-17.6 \mathrm{~K}_{2} \mathrm{O}$, and low amounts of $\mathrm{FeO}, \mathrm{MgO}$ and $\mathrm{CaO}$ (0-0.2, 0-0.1 and 0.4-3.6, respectively). Such compositions are very close to synnyrites and their varieties intermediate to nepheline syenites. The appearance of similar melts seems to be related to high differentiation of alkaline magmas in the close system conditions. This phenomenon is extremely rare in the nature.
\end{abstract}

Key words: synnyrites, nepheline, kalsilite, K-feldspar, apatite, melt inclusions, genesis.

Сынныриты являются очень редкими ультракалиевыми породами - рудами, из которых можно получить глинозем и бесхлорные калийные удобрения (Соболев и др., 1982). В их химическом составе отмечается (мас. \%): 52-53 $\mathrm{SiO}_{2}$, до 22-25 $\mathrm{Al}_{2} \mathrm{O}_{3}$ и 17-19 K $\mathrm{K}_{2}$. В России сынныриты распространены на Сыннырском, Сакунском и Маломурунском массивах. Наиболее крупные их запасы отмечаются на Сыннырском массиве. Последний располагается в Байкальской рифтовой зоне, в пределах Северобайкальского нагорья, имеет зонально-концентрическое строение (Костюк и др., 1990) (рис. 1). Центральное его ядро сложено пуласкитами и гедрумитами. Вокруг ядра распространены сынныриты, которые постепенно сменяются нефелиновыми сиенитами-дитроитами, образуя периферическое кольцо плутона. На севере массива среди дитроитов отмечаются выходы порфировидных псевдолейцитовых сиенитов, а на юго-западе - фойяитов (табл. 1, ан. 1-5). Площадь распространения щелочных пород на массиве превышает 650 км².

Сынныриты макроскопически представляют плотную лейкократовую породу светло-серого и светло-розового цвета, в которой иногда отмечаются шарообразные до 3 см овоиды. Порода состоит из (объем. \%): 65-75 ортоклаза, 8-7 нефелина, 25-17 кальсилита (Панина, Костюк, 1981; Панина, Булгакова, 1981). Некоторое количество нефелина и кальсилита образует мирмекитовые срастания с калиевым полевым шпатом, создавая мирмекитовую и симплектитовую структуры породы. В породе также присутствует небольшое количество апатита, титаномагнетита, биотита, граната, сфена, которые в виде акцессориев располагаются в межзерновом пространстве ортоклаза, а иногда образуют совместные гнезда, шлиры, обособления в сынныритах. В химическом составе калиевого по- 


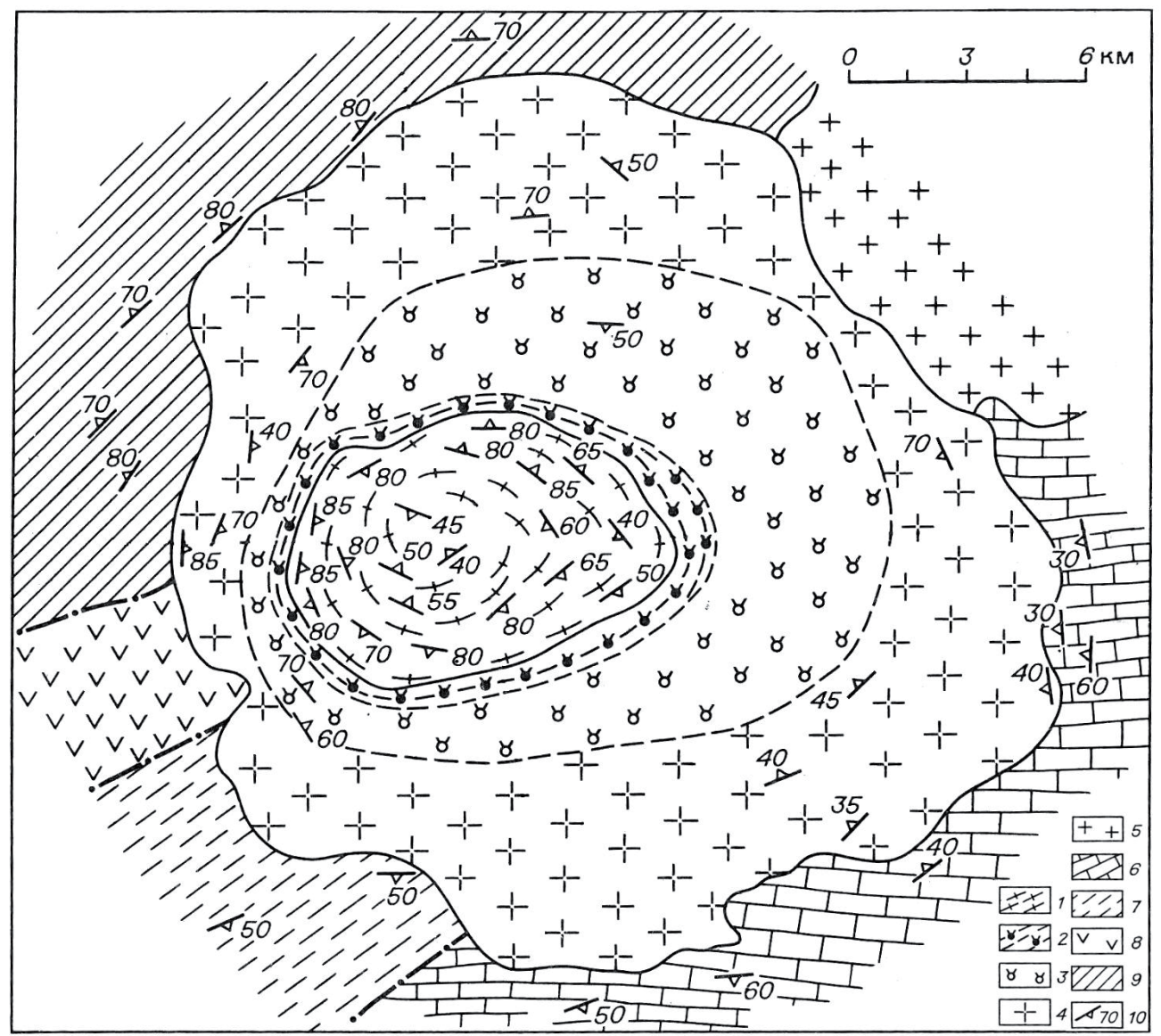

Рис. Строение Сыннырского массива (Костюк и др., 1990).

1 - пуласкиты и гедрумиты второй интрузивной фазы; 2-4 - нефелин-кальсилитовые сиениты первой интрузивной фазы: 2 - сынныриты внутренней зоны, 3 - сынныриты переходной зоны, 4 - нефелиновые сиениты, фойяиты, порфировые псевдолейцитовые сиениты внешней зоны; 5 - гранитоиды витимканского комплекса; 6 - известняки кооктинской свиты; 7 - песчаники, алевролиты и конгломераты холоднинской свиты; 8 - эффузивы основного и 9 - среднего состава сыннырской свиты; 10 - элементы залегания.

Fig. The structure of the Synnyr massif (Kostyk et al., 1990).

1 - pulaskites and hedrumites of the second intrusive phase; 2-4 - nepheline-kalsilites syenites of the first intrusive phase: 2 - synnyrites of the inner zone; 3 - synnyrites of the transition zone; 4 - nepheline syenites, foyaites, pseudoleucite porphyritic syenites of the outer zone; 5 - granitoids of Vitimkansky complex; 6 - limestones of Kooktinsky series; 7 - sandstones, siltstones and conglomerates of Kholodninsky series; 8 - effusive rocks of basic and 9 - of middle composition Synnyrsky series; 10 - elements of the occurrence.

левого шпата и кальсилита среди щелочных элементов присутствует только калий (табл. 1, ан. 6 и 10), а в нефелине (табл. 1, ан. 8) содержится максимальное (до 8 мас. \%) количество К О. Апатит содержит 1.2-3.3 мас. \% SrO и около 3 мас. \% F. Гранат представлен меланитом (табл. 1, ан. 12 и 13, соответственно).

Расплавных включений в калиевом полевом шпате фельдшпатоидах очень мало и они очень мелкие. В апатите включений гораздо больше, особенно в апатитовых шлирах и обособлениях. Среди включений отмечаются первичные и вторичные. Включения имеют разнообразную форму: призматическую, неправильную, округлую. Первичные включения преимущественно тонко-, реже грубораскристаллизованы. Газовый пузырь обычно отсутствует. В грубораскристаллизованных включениях среди дочерних фаз установлен калишпат, нефелин и рудный минерал. Калишпат и кальсилит, как и породообразующие минералы, представлены крайне калиевыми безнатриевыми разновидностями, а нефелин по составу близок к предельному по насыщению калием (табл. 1, ан. 7, 9, 11). 
Таблица 1. Химический состав пород (1-5) и минералов из сынныритов (6-12)

Сыннырского массива,мас. \%.

Table 1. Chemical composition of rocks (1-5) and minerals from synnyrites (6-12) of the Synnyr massif, wt.\%.

\begin{tabular}{|c|c|c|c|c|c|c|c|c|c|c|c|c|c|}
\hline $\begin{array}{c}\text { компо- } \\
\text { ненты }\end{array}$ & 1 & 2 & 3 & 4 & 5 & 6 & 7 & 8 & 9 & 10 & 11 & 12 & 13 \\
\hline $\mathrm{SiO}_{2}$ & 55.43 & 55.58 & 52.93 & 54.82 & 54.88 & 64.10 & 62.89 & 42.57 & 41.98 & 38.14 & 38.79 & 0.05 & 32.85 \\
\hline $\mathrm{TiO}_{2}$ & 0.98 & 0.52 & 0.77 & 0.16 & 0.05 & 0.10 & 0.09 & 0.00 & 0.00 & 0.06 & 0.00 & 0.00 & 6.30 \\
\hline $\mathrm{Al}_{2} \mathrm{O}_{3}$ & 15.02 & 22.13 & 19.82 & 22.52 & 23.20 & 18.15 & 17.47 & 32.09 & 33.53 & 31.41 & 30.51 & 0.00 & 0.67 \\
\hline $\mathrm{FeO}$ & 7.07 & 2.73 & 4.54 & 1.57 & 1.02 & 0.15 & 0.05 & 1.04 & 0.32 & 0.49 & 0.28 & 0.00 & 24.28 \\
\hline $\mathrm{MnO}$ & 0.12 & 0.04 & 0.04 & 0.01 & 0.02 & 0.00 & 0.00 & 0.00 & 0.00 & 0.00 & 0.00 & 0.00 & 0.52 \\
\hline $\mathrm{MgO}$ & 2.95 & 0.59 & 1.73 & 0.58 & 0.24 & 0.00 & 0.00 & 0.00 & 0.00 & 0.00 & 0.02 & 0.01 & 0.17 \\
\hline $\mathrm{CaO}$ & 4.98 & 0.91 & 2.96 & 0.72 & 0.27 & 0.03 & 1.18 & 0.00 & 0.00 & 0.05 & 0.53 & 53.51 & 30.71 \\
\hline $\mathrm{Na}_{2} \mathrm{O}$ & 3.25 & 5.89 & 2.16 & 1.57 & 0.72 & 0.00 & 0.98 & 15.44 & 14.62 & 0.00 & 1.10 & 0.19 & 0.76 \\
\hline $\mathrm{K}_{2} \mathrm{O}$ & 7.32 & 10.12 & 11.88 & 16.50 & 18.38 & 16.97 & 15.15 & 8.05 & 9.43 & 28.44 & 27.32 & 0.01 & 0.18 \\
\hline $\mathrm{BaO}_{2}$ & 0.72 & 0.00 & 0.64 & 0.17 & 0.00 & 0.00 & 0.00 & 0.00 & 0.00 & 0.00 & 0.00 & 0.07 & 0.00 \\
\hline $\mathrm{P}_{2} \mathrm{O}_{5}$ & 0.29 & 0.07 & 0.38 & 0.06 & 0.03 & 0.00 & 0.00 & 0.00 & 0.00 & 0.00 & 0.00 & 39.47 & 0.00 \\
\hline $\mathrm{F}$ & 0.35 & 0.19 & 0.24 & 0.00 & 0.00 & 0.00 & 0.00 & 0.00 & 0.00 & 0.00 & 0.00 & 3.01 & 0.00 \\
\hline $\mathrm{O} / \mathrm{F}$ & 0.15 & 0.08 & 0.10 & 0.00 & 0.00 & 0.00 & 0.00 & 0.00 & 0.00 & 0.00 & 0.00 & 1.29 & 0.00 \\
\hline сумма & 98.28 & 98.66 & 97.95 & 98.68 & 98.81 & 99.50 & 97.81 & 99.19 & 99.88 & 98.59 & 98.55 & $97.15^{*}$ & 96.44 \\
\hline
\end{tabular}

Примечание. Породы: 1 - пуласкиты; 2 - нефелиновые сиениты; 3 - порфировидные псевдолейцитовые сиениты; 4, 5 - сынныриты. Минералы: 6, 7 -калишпат (6- породообразующий, 7 - дочерняя фаза из включения); 8, 9 - нефелин (8 - породообразующий, 9 - дочерняя фаза); 10, 11 - кальсилит (10 - породообразующий, 11 - дочерняя фаза из включения); 12 - апатит; 13 - гранат. * В том числе 2.55 мас. \% SrO. Химический состав пород определялся методом мокрой химии.

Note. Rocks: 1 - pulaskites; 2 - nepheline syenites; 3 - pseudoleucite porphyritic syenites; 4, 5 - synnyrites. Minerals: 6 , 7 - K-feldspar (6 - rock forming mineral, 7 - daughter phase); 8, 9 - nepheline ( 8 - rock forming, 9 - daughter phase); 10,11 - kalsilite (10 - rock forming mineral, 11 - daughter phase); 12 - apatite; 13 - garnet. *Including 2.55 wt. \% SrO. Chemical composition of rocks was determined of wet chemistry method.

Для гомогенизации включений применялась созданная в лаборатории термобарогеохимии ИГМ СО РАН совмещенная с микроскопом термокамера, позволяющая нагревать препарат до $1340-1400^{\circ} \mathrm{C}$. Химический анализ дочерних фаз и закаленных после гомогенизации расплавных включений проводился на рентгеноспектральном микроанализаторе «Camebax-micro». Определения повторялись не менее двух раз для каждой точки.

Как показали эксперименты, вторичные включения являются газово-жидкими, гомогенизируются при $275-365^{\circ} \mathrm{C}$. При нагревании первичных раскристаллизованных расплавных включений подплавление дочерних фаз наблюдается около $560-670^{\circ} \mathrm{C}$. При $750-800^{\circ} \mathrm{C}$ оформляется газовый пузырь. Интенсивное плавление содержимого включений происходит при $1000-1070^{\circ} \mathrm{C}$. При дальнейшем повышении температуры газовый пузырь лишь незначительно уменьшается, а при $1150-1200^{\circ} \mathrm{C}$ происходит растрескивание апатита и включения теряют свою герметичность.

Микрозондовый анализ показал, что в химическом составе включений, прогретых до 1100-1150 ${ }^{\circ}$ С, содержится (мас. \%): 53-56 $\mathrm{SiO}_{2}, 22-24 \mathrm{Al}_{2} \mathrm{O}_{3}$ и 12.4-17.6 $\mathrm{K}_{2} \mathrm{O}$ (табл. 2). То есть, часть законсервированных во включениях расплавов (табл. 2, ан. 4-7) отвечает химическому составу сынныритов, другая часть (табл. 2, ан. 1-3) - промежуточному составу между сынныритами и нефелиновыми сиенитами Сыннырского массива (сравнить с ан. 2, 4, 5 табл. 1). Надо полагать, что расплавы, наиболее близкие по составу к сынныритам, отвечают наиболее отдифференцированным исходным расплавам по сравнению с расплавами промежуточного состава. Следовательно, сынныриты образовались из остаточных исходных щелочных расплавов при температурах не ниже $1100-1150^{\circ} \mathrm{C}$ в процессе дифференциации в закрытых магматических условиях. Предположение о том, что сынныриты могут быть остаточным продуктом кристаллизационной дифференциации исходной щелоч- 
ной магмы было ранее сделано на основании сопоставления химического состава остаточных стекол в частично раскристаллизованных включениях из пироксена различных щелочных базальтоидов и габброидов (Панина, 1983; Костюк и др., 1986).

Таблица 2. Химический состав прогретых расплавных включений в апатите сынныритов, мас. \%.

Table 2. Chemical composition of heated melt inclusions in apatite of synnyrites, wt. \%.

\begin{tabular}{|c|c|c|c|c|c|c|c|}
\hline компоненты & 1 & 2 & 3 & 4 & 5 & 6 & 7 \\
\hline $\mathrm{SiO}_{2}$ & 56.69 & 52.86 & 54.44 & 55.11 & 56.01 & 53.61 & 53.65 \\
\hline $\mathrm{TiO}_{2}$ & 0.00 & 0.00 & 0.00 & 0.00 & 0.14 & 0.00 & 0.00 \\
\hline $\mathrm{Al}_{2} \mathrm{O}_{3}$ & 23.10 & 23.30 & 25.01 & 22.00 & 22.57 & 24.17 & 21.90 \\
\hline $\mathrm{FeO}$ & 0.07 & 0.12 & 0.29 & 0.08 & 0.00 & 0.08 & 0.00 \\
\hline $\mathrm{MnO}$ & 0.05 & 0.01 & 0.02 & 0.00 & 0.00 & 0.00 & 0.00 \\
\hline $\mathrm{MgO}$ & 0.00 & 0.00 & 0.00 & 0.00 & 0.00 & 0.00 & 0.01 \\
\hline $\mathrm{CaO}$ & 3.61 & 2.70 & 1.41 & 1.12 & 0.00 & 0.43 & 0.73 \\
\hline $\mathrm{Na}_{2} \mathrm{O}$ & 1.09 & 3.17 & 4.46 & 2.66 & 1.31 & 3.28 & 1.93 \\
\hline $\mathrm{K}_{2} \mathrm{O}$ & 13.59 & 14.66 & 14.08 & 15.30 & 15.31 & 15.99 & 17.16 \\
\hline $\mathrm{P}_{2} \mathrm{O}_{5}$ & 0.23 & 0.59 & 0.03 & 0.05 & 0.00 & 0.00 & 0.29 \\
\hline сумма & 98.50 & $97.72^{*}$ & 99.74 & $96.38^{*}$ & $96.20^{*}$ & 97.56 & $96.06^{*}$ \\
\hline
\end{tabular}

Примечание: * В сумме также присутствует: № $2-0.19 \mathrm{Cl}$ и $0.12 \mathrm{SO}_{3}$; № 4 - $0.06 \mathrm{SO}_{3}$; № 5 - $0.86 \mathrm{SrO}$; № $7-0.39 \mathrm{Cl}$.

Было установлено, что остаточные стекла включений из этих пород по химическому составу довольно близки между собой, характеризуются высоким количеством $\mathrm{K}_{2} \mathrm{O}$ и $\mathrm{Al}_{2} \mathrm{O}_{3}$ при резко пониженном содержании $\mathrm{FeO}$, особенно $\mathrm{MgO}$ и $\mathrm{CaO}$ при относительно стабильном количестве $\mathrm{Na}_{2} \mathrm{O}$. Было отмечено, что возможности появления в природе условий, соответствующих полностью закрытым крупным системам (наподобие расплавным включениям), ограничены и появление сынныритов является редким исключительным случаем.

Работа выполнена в рамках государственного плана научно-исследовательских работ (проект №330-2016-0005) при финансовой поддержке РФФИ (проект №17-05-00285a).

\section{Литература}

1. Костюк В.П., Панина Л.И., Жидков А.Я., Орлова М.П., Базарова Т.Ю. Калиевый щелочной магматизм Байкало-Становой рифтогенной системы. Новосибирск: Наука. 1990. 234 с.

2. Костюк В.П., Базарова Т.Ю., Панина Л.И., Вавилов М.А. О дифференциации щелочных базальтоидов и возможном образовании высококалиевых природных расплавов // Геология и геофизика. 1986. № 2. С. 79-85.

3. Панина Л.И., Костюк В.П. О составе симплектитовых срастаний в сынныритах // Геология и геофизика. 1989. № 8. С. 126-132.

4. Панина Л.И. Образование высококалиевых богатых глиноземом расплавов // Геология и геофизика. 1983. Т. 24. № 4. С. 34-40.

5. Панина Л.И., Булгакова Е.Н. Вещественный состав сынныритов, их генезис и апатитоносность Сыннырского плутона / Проблемы хозяйственного освоения зоны Байкало-Амурской магистрали. Новосибирск. 1981. C. 83-91.

6. Соболев В.С., Костюк В.П., Панина Л.И., Андреев Г.В., Пак А.С., Шобогоров П.Ч., Бгатов В.И. О проблеме сынныритов // Магматизм и метаморфизм зоны БАМ и их роль в формировании полезных ископаемых. Новосибирск: Наука. 1982. С. 102-110. 